\title{
STREAM (Spatiotemporal Research Infrastructure for Early Modern Brabant and Flan- ders): Sources, Data and Methods
}

Isabelle Devos ${ }^{1}$, Torsten Wiedemann ${ }^{1}$, Ruben Demey ${ }^{1}$, Sven Vrielinck ${ }^{1}$, Sofie De Veirman ${ }^{1}$, Thijs Lambrecht $^{1}$, Philippe De Maeyer ${ }^{2}$, Elien Ranson ${ }^{2}$, Michiel Van den Berghe ${ }^{2}$, Glenn Plettinck ${ }^{3}$, Anne Winter ${ }^{3}$

1: History Department, Ghent University

2: Geography Department, Ghent University

3: History Department, Vrije Universiteit Brussel

Corresponding author: Isabelle Devos, History Department, Ghent University, Isabelle.Devos@ugent.be

Biographical note: Isabelle Devos is Associate Professor at the History Department of Ghent University, Belgium. Over the years her research has revolved around social and economic issues of the early modern period and the long nineteenth century in a comparative perspective, with a particular focus on demography.

\begin{abstract}
This article presents the technical characteristics of the Belgian STREAM-project (20152019). The goal of STREAM is to facilitate and innovate historical research into local and regional processes through the development of a spatiotemporal infrastructure for early modern Brabant and Flanders, two of the most urbanized and developed areas of pre-industrial Europe. To this end, STREAM systematically collects a range of key data from a diversity of historical sources to provide a geographically comprehensive and long-run quantitative and spatial account of early modern society at the local level (parishes, villages, towns) regarding territory, transport, demography, agriculture, industry and trade, related to the development of a tailored historical geographical information system (GIS) based on the well-known Ferraris map (1770-1778). This article discusses the possibilities and pitfalls of the data collection and the construction of a spatial infrastructure for the pre-statistical era.
\end{abstract}

Keywords: spatial history, digital history, data infrastructure, GIS, economic history, historical demography, Belgium 


\section{STREAM (Spatiotemporal Research Infrastructure for Early Modern Brabant and Flan- ders): Sources, Data and Methods}

\section{INTRODUCTION}

High-level historical research is extremely dependent upon access to primary source materials. Over the last decade the demand for large-scale databases in historical research has increased enormously (Digital History). Due to the powerful advances in ICT, there are hardly any technological limitations to the development and analysis of large datasets, while the integration of geographical information systems (GIS) has greatly enriched the uses that can be made of historical databases. Spatial analysis has enabled historians not only to visually present their research results, but more importantly to use space to integrate, collect and study historical data in new ways. This geographical approach to history (Spatial History) has proved its usefulness and reliability over the past decade and has had a significant impact on the progress of historical research, in particular of the nineteenth century. ${ }^{1}$

For the early modern period (ca. 1500-1850), the Cambridge Group for the Study of the Population and Social Structure (CAMPOP) set up an impressive regional data infrastructure for England. Based on the infrastructure, Shaw-Taylor and Wrigley showed that in some areas of England the economy was far more advanced by 1750 than had previously been supposed and suggest that economic growth and population change in the two preceding centuries must have been decisive in bringing about the divergence of England. ${ }^{2}$ Yet, as they rightly point out, their argument is problematic in the sense that their account - as that of others ${ }^{3}$ - highlights the country's exceptional demographic and economic history, without being able to rely on comparable data for the European continent. ${ }^{4}$

In Belgium, early modern historians are insufficiently able to profit from these new research opportunities because of the absence of suitable databases and GIS infrastructures that collect and integrate original data from archival and manuscript data on a local level for a sufficiently large territory. While medieval and modern historians have built a solid tradition in developing various tools facilitating the study of primary sources and statistics, most early modern sources for Belgium are only available on paper in manuscript form in various archives. The connection between such archival data and digitized repositories so far remains poorly developed. Likewise, as early modern maps are often available only on paper or raster images, historians have been slow at bringing a geographical dimension to analyses of the pre-industrial world. According to Wrigley, the creation of historical maps is nonetheless indispensable for the articulation of new historical insight and a necessary prerequisite for detecting regional patterns and temporal changes which might otherwise remain unnoticed. ${ }^{5}$ As a result, our knowledge of the Belgium's social and economic history during the early modern period is characterized by a strong fragmentation. On the one hand, there are hundreds of micro studies examining different phenomena and processes at the local level. Although these works are often of excellent quality and high scientific relevance, the extent to which the results can be generalized is often questionable. On the other hand, there are many studies that describe society at the macro level. They usually lack the necessary detail to reach a deeper understanding of social processes and geographical dimension of population patterns, 
social change and economic developments within countries. This imbalance is due to a lack of quantitative studies providing a comprehensive description of Belgium's early modern society. The collection of quantitative information for the early modern period is a labour intensive task as the available sources are not easily quantifiable for research purposes.

To this end, the STREAM-project (www.streamproject.ugent.be) carried out by historians and geographers at Ghent University and the Vrije Universiteit Brussel, is currently systematically collecting a range of key data from a diversity of historical sources in order to provide a geographically comprehensive and long-run quantitative and spatial account of early modern society at the level of localities (parishes, villages, towns). ${ }^{6}$ As such, STREAM joins in with and contributes to recent developments in digital and spatial history. Its goal is to facilitate and innovate historical research into local and regional processes through the development of a spatiotemporal research infrastructure for early modern Brabant and Flanders that allows for spatial analysis of key historical data. The Duchy of Brabant and the County of Flanders, two of the most urbanized and developed areas of pre-industrial Europe, are regions par excellence to tackle new research questions and re-examine 'old questions', such as the debate on the birth of modern economic growth and our understanding of the preconditions of Europe's leading economic and demographic role in the eighteenth and nineteenth century.

The development of the STREAM spatial data infrastructure involves two strands of data collection. On the one hand, a series of high-quality datasets relating to the population and social and economic structure of the Duchy of Brabant and County of Flanders between 1550 and 1815. On the other hand, a geographical information system is developed to spatially structure and map the historical data, which also allows for manipulation and analysis of the data at different spatial levels, from parishes to bishoprics, castellanies and counties. Working backwards from the map of Ferraris (1770-1778), the GIS not only includes administrative boundaries, but also key data on roads and waterways, building density and economic infrastructure in the second half of the eighteenth century. The combination of both will result in a geographically comprehensive and long-run quantitative and spatial account of early modern society at the level of localities. This account will improve our understanding of the timing of regionally and locally differentiated economic, social and demographic developments in the long run and bring novel insight into the origins of economic and demographic growth in Europe in general and Brabant and Flanders in particular. The STREAM infrastructure will be fully operational by 2020 .

In what follows, we first provide a short overview of the political and socio-economic history of the Duchy of Brabant and the County of Flanders (section 2). Next, we discuss the data collection (section 3 ). Finally, we consider the construction of a spatial infrastructure for the pre-statistical area, by means of two tailor-made GIS tools: Ferraris Vectorized and Ferraris Georeferenced (section 4).

\section{A REGIONAL APPROACH: BRABANT AND FLANDERS}

In the STREAM project, the focus is on the Southern Netherlands, and two of its core regions the Duchy of Brabant and the County of Flanders (figure 1). From 1555 onwards the Southern Low Coun- 
tries were in possession of successively the Spanish Habsburgs and, after the Spanish War of Succession (1701-1714), the Austrian Habsburgs. ${ }^{7}$ The region was united politically only to the extent that the different regional entities (castellanies, duchies and seigneuries) recognized the same personal ruler, who from 1482 on was a Habsburg. Throughout the early modern period, the Southern Low Countries therefore formed a composite state within the larger territories of the Habsburg dynasties. The Habsburg rule ended in 1794, when the Southern Netherlands and the principality of Liège were conquered by France. The Duchy of Brabant and the County of Flanders were two of the most urbanized and developed areas of pre-industrial Europe. Between c. 1500 and 1800, population in these areas doubled, while economic growth was gradual, though not considerably slower than in Britain. ${ }^{8}$ Both regions, comprising in turn 538 and 574 parishes, represent interesting cases for comparative analysis into socio-economic and demographic change in the early modern period, as variations within these regions (together $12,000 \mathrm{~km}^{2}$ ) was far greater than in many other parts of Europe, with regard to soil types (clay, sandy to loamy soils), rural systems (market-oriented agriculture, subsistence agriculture and proto-industrial areas), urban types (regional market towns, ports, large cities oriented towards urban export), labour relations (from areas with capitalist labour relations to areas where wage labour was only of marginal importance), poor relief institutions (from formalized, elite-controlled to informal, community-based), transport infrastructure (from relatively isolated areas to areas with a 'modern' network of paved roads), military damages (some areas were spared, other heavily targeted) etc. ${ }^{9}$ Yet although we know already a lot about specific localities in particular sub-periods, we know much less on the economic and demographic history in these areas on a more comprehensive scale.

\section{Figure 1. Duchy of Brabant and County of Flanders with territorial subdivisions}

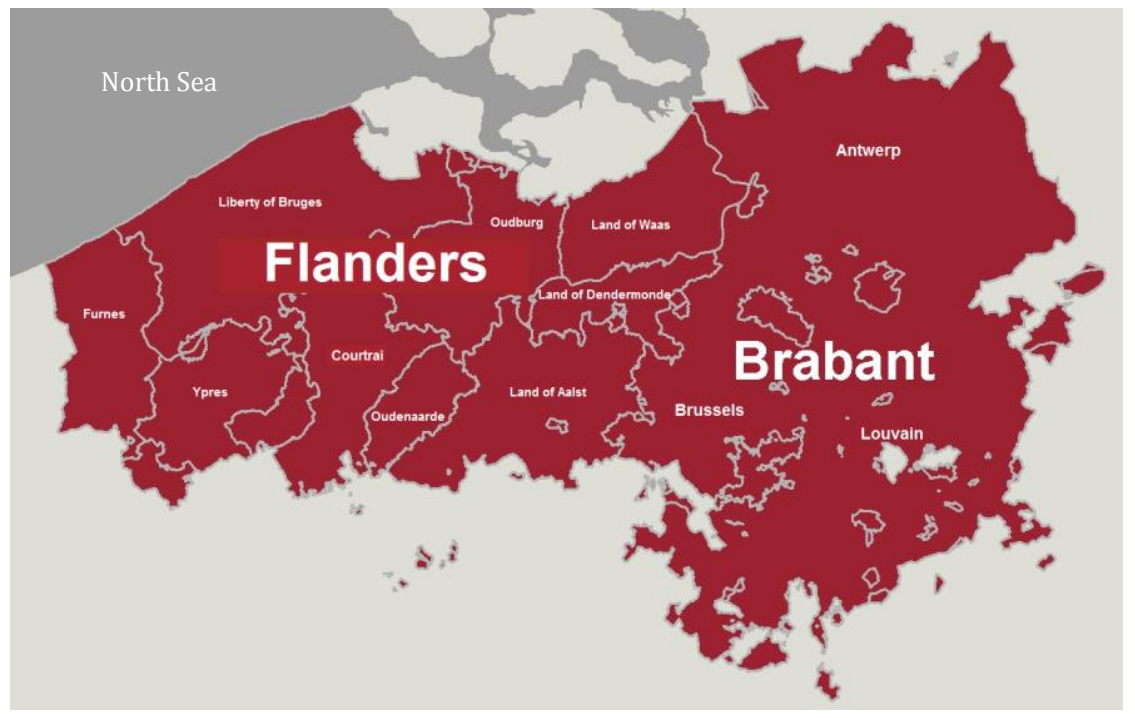

Source: UGent Quetelet Center, Stream (2017).

Note: The study area of STREAM covers 17 administrative entities with fiscal and judicial powers, not including the territories annexed by France and the Dutch Republic in the seventeenth century. The Duchy of Brabant consists of the quarters (kwartieren) of Antwerp, Brussels and Louvain, whereas the County of Flanders comprises the castellanies (kasselrijen) of Furnes, Ypres, Courtrai, Oudenaarde, the Liberty of Bruges, Oudburg, Vier Ambachten, Land of Aalst, Land of Dendermonde, and Land of Waas. 
The data collected via STREAM will allow to shed light on the geography of the early modern economy and population in Brabant and Flanders, and to improve our understanding of the timing and articulation of regionally and locally differentiated economic, social and demographic developments in the long run. This will permit to link up with current discussions on the origins of modern economic and population growth and with recent historiographical trends that strongly emphasize a regional approach. As a result, the results of the STREAM project have the potential to transcend the time- and place- specificity of research, and represent a new step in the socio-economic and demographic history of early modern Europe.

\section{LARGE-SCALE DATA COLLECTION}

The period before the nineteenth century is known as the 'prestatistic era', implying that aggregated data on demographic, economic and social developments for this period is scarce. Before the late eighteenth century, governments organized few censuses or surveys about the country, its citizens and society, in a way that transcended the local level. To discover 'the big picture', historians have to retrieve data by tapping into a wide array of sources and quantifying them. This is arduous for several reasons. First, experience with old terminology, language and writing is required. Second, an abundance of sources containing micro data must be consulted and data must be counted prior to the compilation of usable data series. Moreover, to be able to apply quantitative and computerized research techniques, the original data must comply with strict criteria, such as continuity and regularity. This is not always the case as historical documents often contain gaps and display a lack of standardization. Because of these limitations a lot of preparatory work is needed to convert the sources into solid research material.

During the last decades, local historians and historical societies have covered and collected a wide range of sources from status animarum to taxation lists, while numerous genealogists in search of their ancestry have rifled through a multitude of parish registers. Their efforts have led to the creation of many databases documenting baptisms, marriages and burials. None of these data have, however, been collected in a systematic way. No effort so far has been undertaken to bring source collections together, in combination with the systematic collection of raw data to identify the 'blind spots' where further collection is needed. As a result, we lack an overview of the timing and geography of demographic and economic change between the mid sixteenth and early nineteenth centuries. Through the creation of a series of major high-quality datasets relating to population development and economic change in early modern Brabant and Flanders, STREAM meets this need and will make valuable quantitative data available for early modern research.

In the data collection, STREAM takes into account all quantitative and quantifiable sources on the basis of which regionally diverse datasets can be compiled. The applicability and suitability of the early modern data for scientific research is the main selection criteria for incorporating sources into the project. Priority is given to data collectable from sources at the local level (parishes, villages, towns) for wide geographical areas. For instance, it concerns the collection and critical assessment of crosssectional data derived from population and hearth surveys $(1571,1614,1695,1702,1748,1755,1796)$, 
fiscal registers $(1571,1615,1748,1755)$ and surveys on agriculture $(1556,1709,1724,1771)$, industry $(1738,1764)$, poor relief $(1695,1702,1748,1755,1808)$, seasonal migration $(1800,1811)$, cadastral surveys $(1570,1686,1815)$, together with time series on enumeration of communicants, and on annual births, deaths and marriages collected from parish and civil registers between 1550 and 1815. Data regarding the Brabant and Flemish territory are collected by means of the Ferraris Vectorized tool (see next section). Still, STREAM is not limited to collecting, cleaning and harmonizing early modern data into one extensive repository, it also consists of a critical appraisal of the data by drawing up a metadescription and source criticism. As such, it will allow users to assess changes in data definitions and discuss issues of data comparability

Although the STREAM infrastructure is work in progress, the collected data so far already allow to show its exciting analytical possibilities. ${ }^{10}$ By way of example, we refer to the two very recent studies. A study by Devos and Van Rossem, for example, was able to highlight the tremendous variations in mortality levels across Brabant and Flanders at successive points in time by mapping the annual numbers of burials and baptisms gathered for ca. 330 parish registers via STREAM. As a result, certain areas with distinct health experiences could be identified, in particular the exceptionally high mortality in the coastal areas. The authors pointed to topography as an important determinant for the differences. ${ }^{11}$ Likewise, correlating STREAM datasets on poor relief, occupational structure and land holdings, Van den Broeck, Lambrecht and Winter examined geographic trends in relief income and expenditure. They concluded that parishes in the coastal areas, dominated by capital-intensive commercial agriculture, were more likely to have high relief incomes, which were distributed among relatively few people. Conversely, those characterized by subsistence-oriented and proto-industrial cottagers or small-scale independent farmers, which were more prominent in the inland areas, were more likely to have less relief income, more relief recipients, and lower hand-outs per recipient. They claim therefore that in early modern Flanders and Brabant different roles were assigned to poor relief: as an instrument for labour regulation or one for social cohesion. ${ }^{12}$

\section{SPATIAL DATA VISUALIZATION AND ANALYSIS: GIS}

Since maps provide an extremely powerful way to organize, investigate and visualize data, STREAM is developing a geography-driven data infrastructure: a historical geographic information system. This HISGIS functions as the backbone of the project: it is responsible for the storage, linkage, editing and presentation of the historical data at the different spatial scales, from parishes to bishoprics, castellanies and counties. It entails, in fact, a tailored digital infrastructure which will allow to place the historical data within their local geographic context - a necessary prerequisite for detecting regional patterns and temporal changes.

The geographic component of the STREAM infrastructure is based on a full coverage basis map, more specifically the map drawn up between 1770 and 1778 by count Joseph Jean François de Ferraris, who was assisted by a staff of about 70 soldiers. The Ferraris map is currently being manually vectorized by the STREAM team and subsequently compared with recent topographic maps to adjust for geometrical 
deviations. To speed up the digitization and georeferencing of the Ferraris map, we created two GIS tools: one for vectorizing the scanned Ferraris map, called Ferraris Vectorized and one for georeferencing the vectorized Ferraris maps, called Ferraris Georeferenced. In what follows, we first describe the context in which the original Ferraris map was created and the difficulties the map entails for current research. Subsequently, we describe the Ferraris Vectorized tool and the development of the spatial infrastructure. This section ends with a short explanation of the Ferraris Georeferenced tool.

\subsection{CARTE DE CABINET OF COUNT JOSEPH DE FERRARIS (1770-1778)}

The starting point for the development of the STREAM HISGIS is the Ferraris map, or in full the Carte de Cabinet des Pays-Bas Autrichiens levée à l'initiative du comte de Ferraris (figure 2). This 1:11520 map of the Austrian Netherlands and the Prince-Bishopric of Liège covers more or less the current territory of Belgium and is as such the only source that provides a very detailed 'national' overview of the delineation and topography of all localities in the late eighteenth century. For historians and geographers, the Ferraris map constitutes a primary source of information on the pre-industrial landscape. ${ }^{13}$

Figure 2. Details of the Ferraris map (1770-1778), Mechelen and Liège.
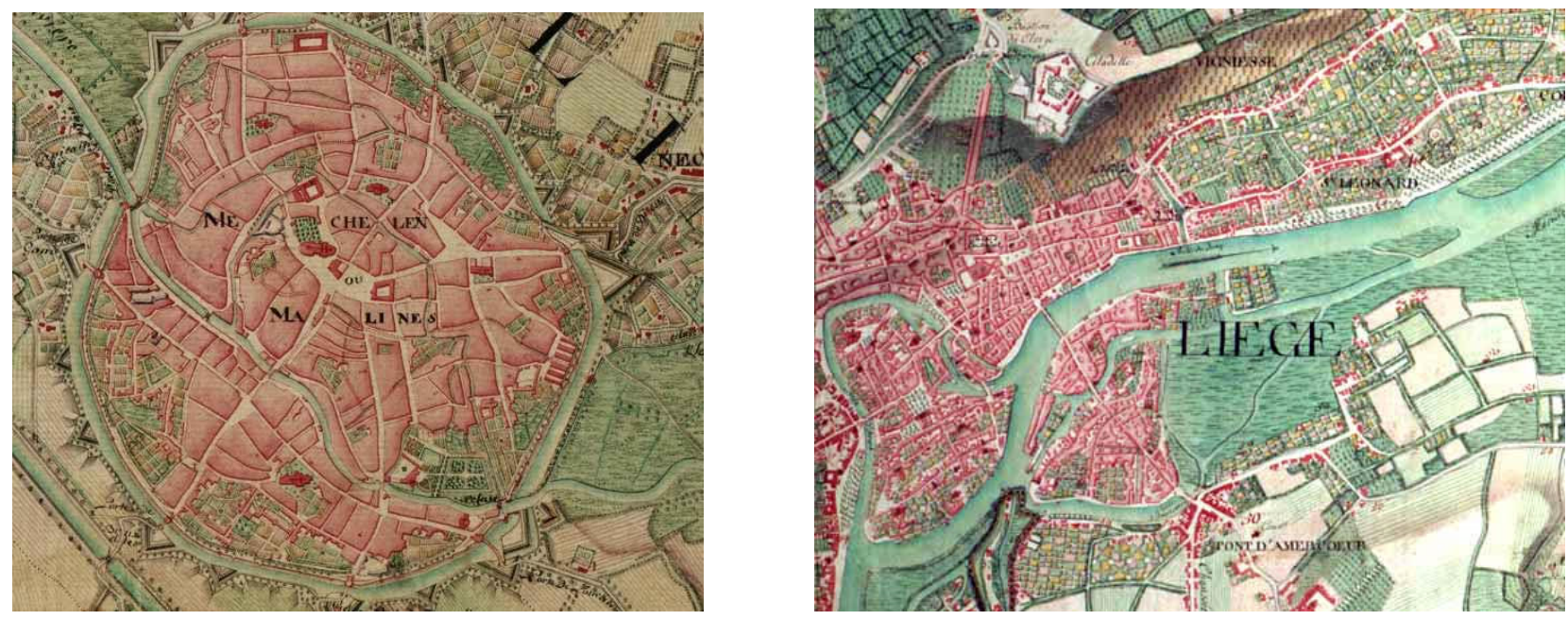

Source: Carte de Cabinet des Pays-Bas Autrichiens levée à l'initiative du comte de Ferraris.

The Carte de Cabinet was drawn up between 1770 and 1778, following the example of the new map of France led by César François Cassini de Thury (Cassini map, 1756-1789). ${ }^{14}$ Three copies of the Ferraris manuscript were produced, each consisting of 275 multicolored sheets $(0,9 \times 1,4 \text { meters each })^{15}$ : one for Empress Maria Theresia (now preserved in The Hague, National Archives), one for Charles de Lorraine, governor of the Austrian Netherlands at the time (now preserved in Brussels, Royal Library of Belgium) and one which was to be preserved in the Chancellery of Court and Nation in Vienna (now preserved in Vienna, Kriegsarchiv) (Bracke 2009). The Viennese copy, which was the first to be drawn up, is used as the starting point of the STREAM project.

The hand drawn Ferraris map contains a lot of historically interesting information. For one thing, it shows the administrative and legal situation of the Austrian Netherlands at the end of the early modern 
period, before the reforms imposed by the French Republic in the 1790s. The borders of counties, duchies and seigneuries are indicated, as well as the rough size of parishes. To this end, each parish church was assigned a number. The same number was written in the houses whose residents belonged to that parish. The map also gives an idea of the extent of urbanization in the Austrian Netherlands. Rural houses were depicted by small red rectangles or squares, while houses in towns and cities were drawn as part of residential blocks (instead of separately). In addition, the map shows the complex road network of paved and unpaved roads, exit roads of polders, waterways, bridges etc.. From the symbols for pine forests, orchards, hedges, meadows, fields, etc. we have an indication of eighteenth-century topography. Because of its level of detail, the Ferraris map is of invaluable importance for contemporary historical and geographic research. Nonetheless, the Ferraris map poses some difficulties for contemporary use. An important obstacle is the interpretation of symbols used by eighteenth-century cartographers. The cartographic symbols used in the eighteenth century were either self-evident or conventional. For example, a church was drawn as a little church and gallows were drawn as they were in reality. Other geographic indicators such as markings of land covering were based on conventions. Land and forest were so common on maps that an easy style for representing them was necessary (figure 3). ${ }^{16}$

Figure 3. Example: symbols on the Ferraris map for different types of vegetation
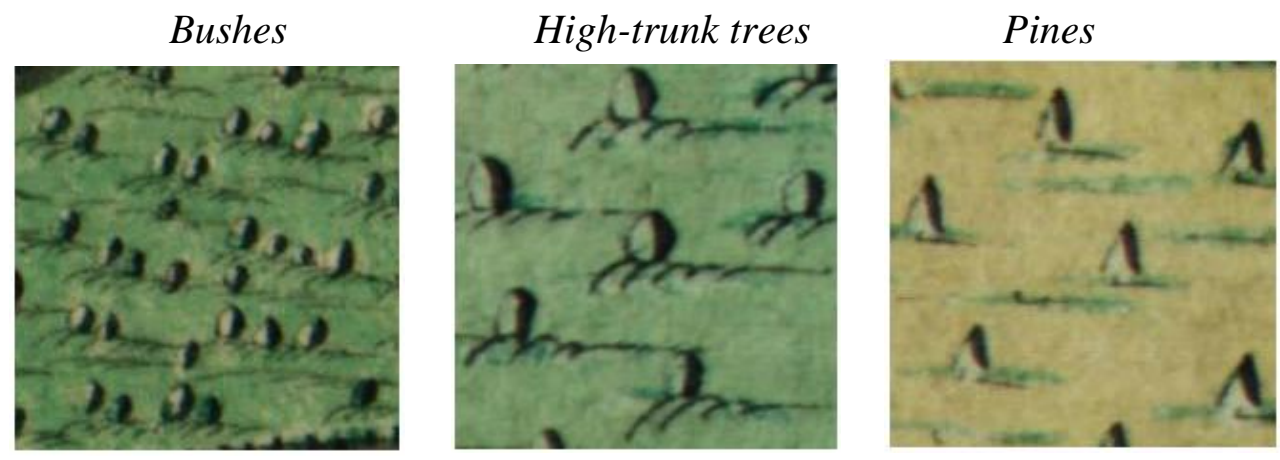

Source: Carte de Cabinet des Pays-Bas Autrichiens levée à l'initiative du comte de Ferraris, sheets 2 (Nieuwpoort) and 188 (Rekem)

At the time when Ferraris's Carte de Cabinet was produced, the need for a legend was not taken for granted. In the case of Ferraris, there is a written key included in the introduction of Ferraris's $M e$ moires, which accompany the Carte de Cabinet (Eclaircissement). However, as this is only a text without visual representation, it is not always straightforward for present-day scholars to distinguish between symbols, especially as they were not always standardized. This probably has to do with the way in which the map sheets were drafted. Usually, the surveyor in the field gave only an indication of the semiotics on his planchet (for example, a 'p' for prez, pasture and a ' $b$ ' for bois, forest) while a cartographer completed the map in his office. As several cartographers, each with their own individual style, continued the work, differences between the sheets could occur. Additionally, we notice that the level of detail decreased as more sheets were finished. ${ }^{17}$ Fortunately, this project can benefit from legendmaking initiatives by contemporary scholars. ${ }^{18}$ 
A second difficulty relates to the determination of borders. This was as much a problem for eighteenthcentury cartographers as it is for scholars today. One of the biggest concerns of Ferraris's contemporaries was a correct representation of borders. The feudal chaos that characterized the frontiers in Ferraris's time was so complex that surveyors made mistakes and considered parts of free states, such as Liège or Stavelot, to be Austrian territories. Through the courtesy of the prince bishop of Liège, the prince abbot of Stavelot and the rulers of the many free states, a rectification of the border sections of the map was carried out between 1777 and 1779. As a result, the Carte de Cabinet often shows a double pattern in the border symbols because the borders were corrected later. ${ }^{19}$

In the development of a GIS for the period before 1800, we are not only faced with difficulties interpreting the eighteenth-century borders, the construction is also complicated by the fact that early modern units of administration, be it ecclesiastical (parishes and bishoprics) or civil (counties, castellanies etc.) are different from the nineteenth-century administrative boundaries (municipalities, departments and provinces). The different content of eighteenth- and nineteenth-century administrative units entails difficulties in merging on the one hand eighteenth- and nineteenth-century data into a longitudinal dataset and on the other hand nineteenth century data with eighteenth century maps (and vice versa). ${ }^{20}$

\subsection{FERRARIS VECTORIZED TOOL}

The STREAM HISGIS is based on the digitization of the Ferraris map. To speed up the digitization process, we developed an online GIS tool for vectorizing the scanned Ferraris map, called Ferraris Vectorized. Vectorizing means that we convert raster data (in this case, scans of Ferraris map sheets) to vector data (a series of digital points, lines, and polygons). Points are used to indicate the position of buildings or structures such as houses, churches, chapels, bridges, mills and gallows. Lines are used to show the geometry of linear features such as different types of roads, rivers, canals and shorelines, but also administrative boundaries and territorial circumscriptions. Polygon features are enclosed areas like forests, pastures, domains and city centers. All these different features put together in a digital form give us a detailed picture of the Belgian territory in the second half of the eighteenth century (figure 4).

The Ferraris Vectorized tool is custom-made to facilitate and accelerate the vectorizing process. Compared to conventional GIS systems, Ferraris Vectorized is more user-friendly due to its simplicity (few buttons), the easy linking of attributes to map elements through standardized drop-down menus and the flexibility with which you can switch between different map layers. The tool is accessible from any web browser and requires no additional software. The result is non-georeferenced vector files in GeoJSON-format, which can be further processed in any standard GIS environment. 


\section{Figure 4. Vectorization process by means of the 'Ferraris Vectorized' tool}

Scan of the Ferraris map (Raster data)
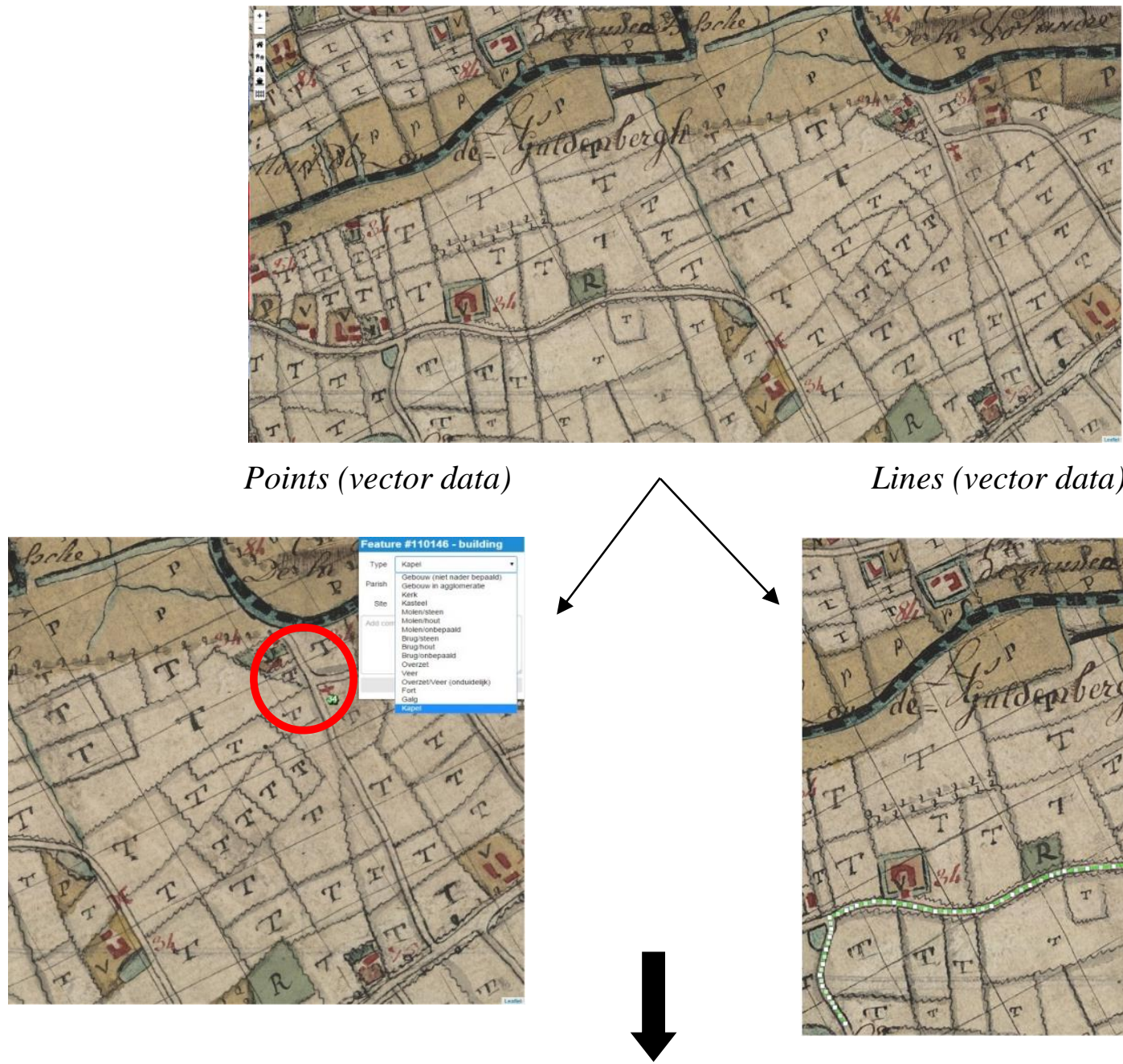

Lines (vector data)

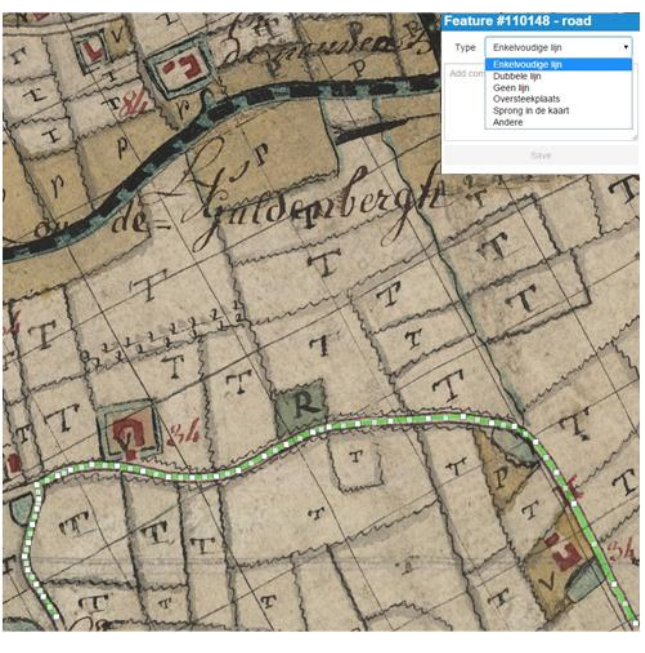

Vector file

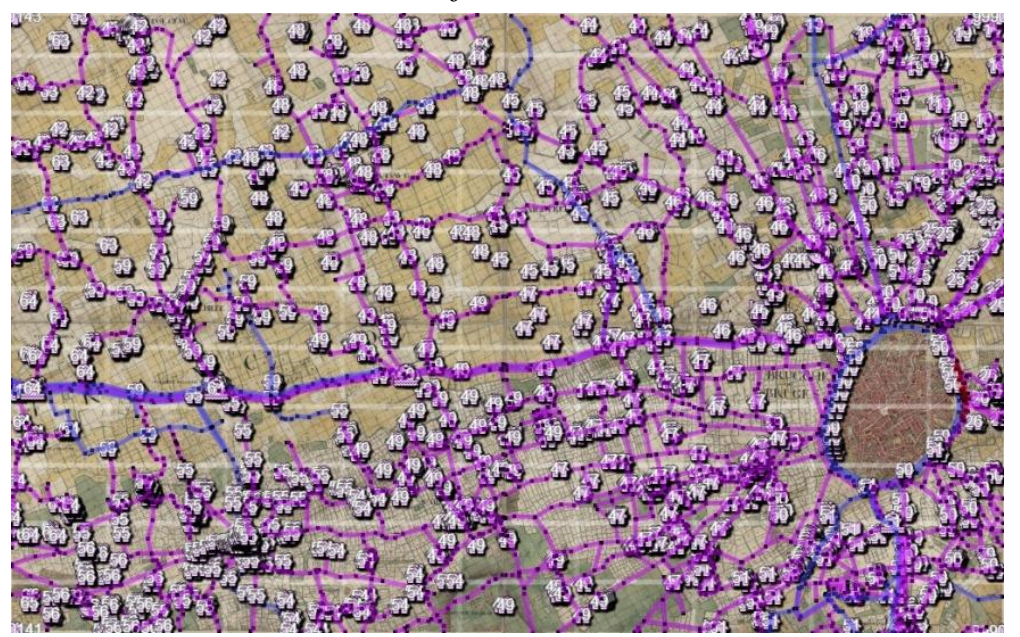


Vectorization entails two types of difficulties. First, we are faced with difficulties in interpreting the symbols on the scanned Ferraris map sheets (see previous section). Second, topological problems arise from the vectorization process in itself. There are different types of topological errors and they can be grouped according to whether the vector feature types are polygons or lines. Topological errors with polygon features can include unclosed polygons, gaps between polygon borders or overlapping polygon borders. A common topological error with line features is that they do not meet perfectly at a point (node). This type of error is called an undershoot when a line feature such as a river does not exactly meet another feature to which it should be connected, and an overshoot if a line ends beyond the line it should connect to. The result of overshoot and undershoot errors are so-called 'dangling nodes' at the end of the lines. Dangling nodes are acceptable in special cases, for example if they are attached to dead-end streets. Figure 5 demonstrates what undershoots and overshoots look like. Over- and undershoot errors most often occur when different map sheets are connected to each other.

\section{Figure 5. Examples of an under- and overshoot error}

Undershoot error

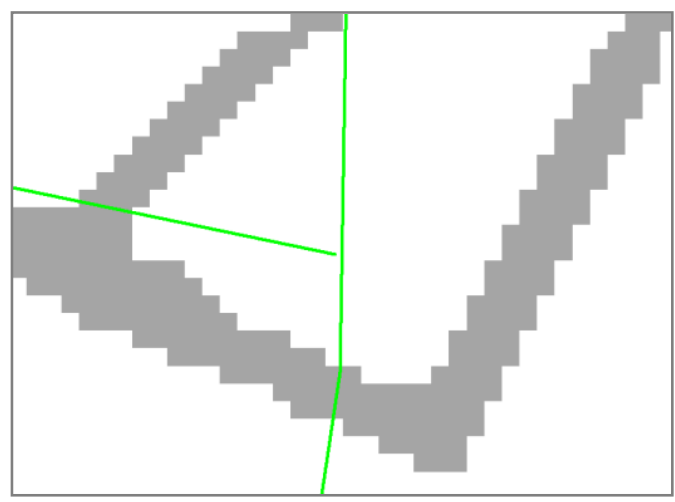

Overshoot error

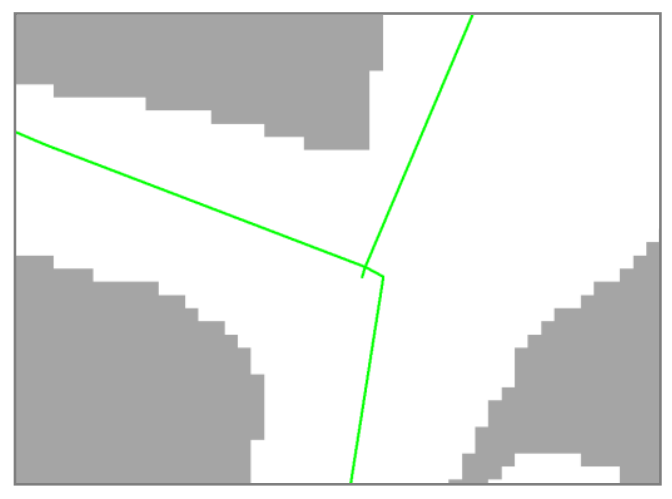

Topological errors break the relationship between features. These errors need to be fixed in order to be able to analyze vector data with procedures like network analysis (e.g. finding the best route across a road network) or measurement (e.g. finding out the length of a river). The technique most often used to fix over- and undershoot errors is snapping. Snapping is an automatic editing operation in which points or features within a specified distance of other points or features are moved to match or coincide exactly with each other's coordinates. This cleaning process, together with the correction of some man-made mistakes such as misidentification (wrong parish name, wrong type of object) contribute to the timeconsuming character of this project.

\subsection{FERRARIS GEOREFERENCED TOOL}

In order to increase STREAM's potential for spatial analysis, we need to relate the collected quantitative data to topographical elements and boundaries as attribute data. This is known as georeferencing. It entails that the historical geographic data, in this case from the Ferraris map, is assigned to a known coordinate system so it can be viewed, queried, and analysed with other geographic data. Therefore, a 
second GIS tool was built by the STREAM team, Ferraris Georeferenced, to compare the line data the roads - from the vectorized Ferraris map (made with Ferraris Vectorized) with the current network of roads and as such create a georeferenced map of the road system that existed between 1770 and 1778 in Brabant and Flanders.

Ferraris Georeferenced is a specific web-based editor tailored to STREAM needs and designed for the purpose of user-friendliness. ${ }^{21}$ As STREAM consists of a collaboration between researchers from different disciplines, Ferraris Georeferenced was custom designed by UGent geographers - as opposed to extending existing GIS tools like QGIS or ArcGIS. Consequently, researchers do have to immerse themselves in all functions available in a typical GIS-platform, which usually results in a slow and limited learning curve. Ferraris Georeferenced, for example, allows to easily compare different source images (historical maps, aerial imagery, soil maps,...) and multiple users can work simultaneously without conflicts. Different historical maps were entered in the Ferraris Georeferenced tool: (1) a map of the current network of roads, provided by the Belgian National Geographic Institute (NGI) in the Lambert projection; (2) this contemporary map layer is placed over the vectorized Ferraris map for comparison. (3) Other maps such as the Vermaelen and Popp maps (nineteenth-century cadastral maps), for which vectorized maps are available, were imported as additional map layers. By means of a slider, it is possible to compare eighteenth (Ferraris) with nineteenth (Popp and Vermaelen) and twentieth century (NGI) road systems.

In the comparison, we start from the current roads map (NGI). Each map sheet of the Carte de Cabinet is roughly positioned onto the modern map through an affine transformation of its four vertices. ${ }^{22}$ Once the map sheet is positioned, the current road network is visualized by purple vector lines, indicating they are in a pending state. When there is a clear resemblance between a present road and a road on the Ferraris map, based on visual interpretation, the purple line turns into a green one by right clicking the segment of the road and choosing 'confirm'. If a current road does not correspond to a road on the Ferraris map, this road is turned orange by right clicking the segment and choosing 'delete'. By choosing 'confirm' or 'delete' for every road segment of the current network, we get a clear picture of which roads were present during the time the Ferraris maps were made. A fourth option is when there is a road present on the Ferraris map that has disappeared in the current network. In that case the missing road has to be digitalized.

During the process of comparison, a few problems can occur. A first complication appears when part of the current road corresponds to the old one and another part does not. In that case, a drawing tool allows to split the road allowing the new created segments to be analyzed separately. Every segment can be split as many times as necessary. A second problem arises when certain roads do not correspond perfectly, but the general shape is present on the Ferraris map. In that case it is useful to consult the Popp map. This cadastral map was edited by Philippe Christian Popp in the nineteenth century and resembles in great detail the current road system. This map was integrated in the software as a separate layer which can be inspected by sliding the Ferraris layer to the left (figure 6). 


\section{Figure 6. Comparison with the POPP map (by means of a scrollbar)}

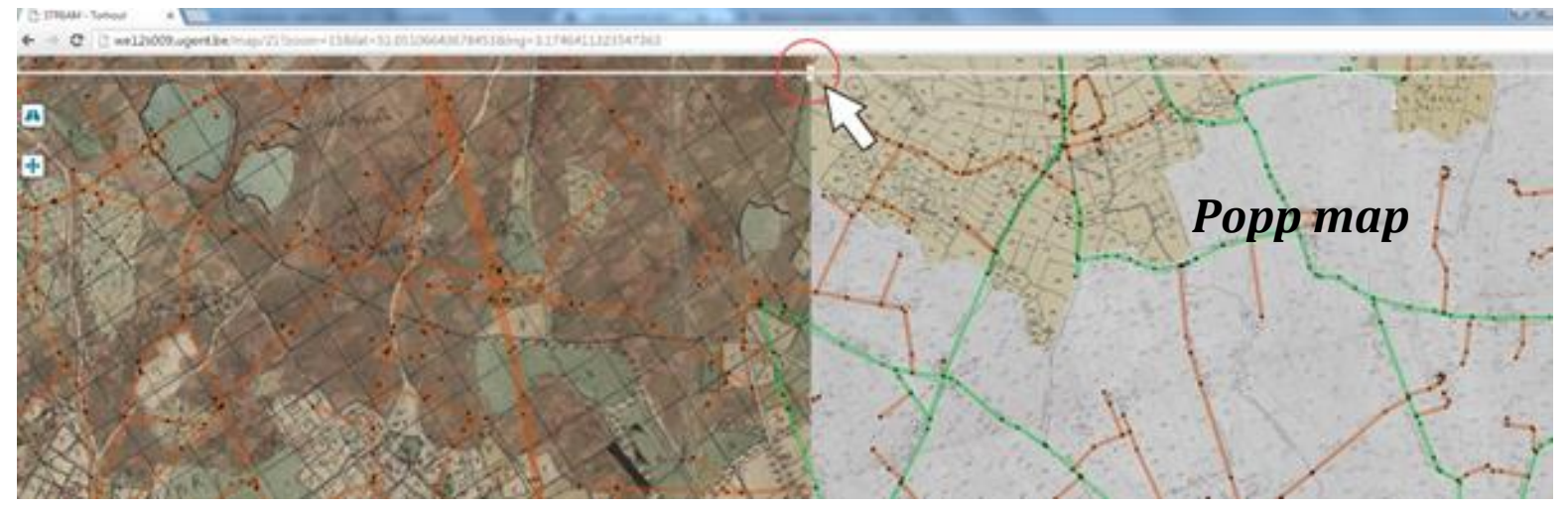

In case the current roads correspond perfectly with those on the Popp map, these roads are selected as 'confirm' since it can be assumed that the differences on the Ferraris map are due to measuring flaws If the Popp map shows little resemblance to the current roads, then these roads are selected as 'delete' since the presence of the general shape on the Ferraris map will then be due to mere coincidence. Since the Popp map is dated after the Ferraris map, it is safe to assume that current roads that are missing on the Popp map, could also not have existed during the time the Ferraris maps were made. In this respect, it is easier to first delete all the roads from the current network that do not correspond to the Popp map, giving that this map is much less difficult to read than the Ferraris map. A third problem is the subjective nature of the interpretation. Even when certain roads seem to correspond with one another, it is still possible that this correspondence is an unfortunate coincidence. Decisions based on visual resemblance or differences therefore need confirmation by combining the visual interpretation with analyses of other cartographic documents.

\section{CONCLUSIONS}

The origins of modern economic and population growth have been the subject of longstanding international debate. At the centre of current discussions are the demographic and economic developments in the early modern period, when the foundations of modern growth were laid. Most of these studies follow either a macro-approach based on 'national' estimates that ignore regional differences or a micro approach using analysis of households and individuals of which the representativeness remains unclear. In recent years, however, a number of methodological and conceptual innovations have opened up to allow new directions and approaches in research. STREAM capitalizes on three of these promising new avenues for research, which we briefly discussed in this article:

(1) A regional approach. Recent research has increasingly argued that questions concerning the interaction between demographic and economic developments in early modern Europe can best be tackled with regional analysis, since social relations and economic activities in pre-industrial times predominantly articulated regionally rather than nationally. By collecting data at the local level and analysing from the local level upwards (bottom-up approach), it is possible to investigate whether and which 
broader regional dynamics can be discerned. In the STREAM data collection, priority is given to data collectable from sources at the local level (parishes, villages, towns) for wide geographical areas in the Duchy of Brabant and the County of Flanders. Brabant and Flanders, as two of the most urbanized and developed areas of pre-industrial Europe represent interesting cases for comparative analysis because of the large socioeconomic and demographic variations within these regions. Moreover, fundamental economic transitions, such as the transformation of the agrarian sector and the rise of industrial production started early here.

(2) The deployment of large scale databases. This development is rapidly gaining access into historical research and is transforming the field of socio-economic and demographic history (Digital History). So far, most exciting databases in the rapidly expanding field of digital history are based on published sources, of which digitization can be partly automated. However, for early modern socio-economic and demographic history, most relevant data are stored only on paper in manuscript form in various archives. Through the implementation of key data from a diversity of sources related to the early modern population and social and economic structure, as illustrated in this article, STREAM will protect and make accessible a multitude of historical data for diverse research applications.

(3) The development of a historical geographic information system. This geographical approach to history (Spatial History) has proved its usefulness and reliability over the past decade and has had a significant impact on the progress of historical research. Spatial analysis enables historians not only to visually present their research results, but more importantly to use space to integrate, collect and interpret historical data in new ways. As most early modern source materials and maps are available only on paper, historians have been slow at bringing a geographical dimension to analyses of the pre-industrial world. Starting from what is considered the first topographic map available for the Southern Netherlands, the Ferraris map (1771-1778), STREAM is developing a historical geographic information system which will allow to place the early modern data within their local geographical context - a necessary prerequisite for detecting regional patterns and temporal changes. The historical HISGIS is developed by means of two GIS tools: Ferraris Vectorized and Ferraris Georeferenced. The objectives of the Ferraris Vectorized and Georeferenced tool are complementary: Ferraris Georeferenced comprises the the digitisation of the historical road network in a geographic reference system. Ferraris Vectorized, on the other hand, aims at digitizing all topographic characteristics - roads, buildings, administrative and judicial entities, etc. - of eighteenth-century Brabant and Flanders. Together, the tools will enable us to study the historical evolution of infrastructure and to make spatio-temporal analyses of the demographic, social and economic data for Flanders and Brabant in order to improve our understanding of regionally differentiated economic, social and demographic developments during the early modern period.

\footnotetext{
${ }^{1}$ See special issue of Journal of Interdisciplinary History, 42 (2011).

${ }^{2}$ L. Shaw-Taylor and E.A. Wrigley, 'Occupational structure and population change', in R. Floud, J. Humphries and P. Johnson, eds., The Cambridge Economic History of Modern Britain (Cambridge, 2014), 53-88.
} 
${ }^{3}$ S. Broadberry et al., British economic growth 1270-1870 (Cambridge, 2015) ; R. Allen, The British Industrial Revolution in Global Perspective (Cambridge, 2009); J. Mokyr, The Enlightened Economy: an Economic History of Britain (New Haven, 2009).

${ }^{4}$ L. Shaw-Taylor, Male Occupational Change and Economic Growth, 1750-1851, End of Award Report (available via CAMPOP, 2007).

${ }^{5}$ E.A. Wrigley, 'The Region as a Unit of Study. History and Geography in Harmony', Romanian Journal of Population Studies, 7 (2013), 107-119.

${ }^{6}$ Funded by the Hercules Foundation (Medium-Scale Research Infrastructure), Research Foundation - Flanders (FWO).

${ }^{7}$ The Northern Low Countries became an independent Republic during the Eighty Years' war (1568-1648). As a result, the Brabant was split into two parts, the north belonging to the Dutch Republic, the south belonging to the Spanish Netherlands

${ }^{8}$ P. Klep, 'Population Estimates of Belgium, by Province (1375-1831)', in: E. Hélin, ed., Historiens et Populations. Liber amicorum Etienne Hélin (Brussels, 1991), 498-507; J. Blomme and H. Van der Wee, 'The Belgian Economy in a LongTerm Historical Perspective: Economic Development in Flanders and Brabant, 1500-1812', Proceedings of the eleventh international economic history congress (Milan, 1994).

${ }^{9}$ I. Devos, T. Lambrecht and R. Paping, 'The Low Countries, 1000-1750', in I. Devos, T. Lambrecht and E. Vanhaute, eds., Rural Economy and Society in North-Western Europe, 500-2000: Making a Living: Family, Income and Labour (Turnhout, 2011).

${ }^{10}$ Some of its research potential was recently demonstrated in two conference sessions devoted entirely to STREAM: in April 2016 at the European Social Science History Conference in Valencia and in September 2016 at the conference of the European Society for Historical Demography in Leuven.

${ }^{11}$ I. Devos and T. Van Rossem, 'Oud, ouder, oudst. Regionale en lokale verschillen in sterfte in het graafschap Vlaanderen tijdens de zeventiende eeuw', Jaarboek De Zeventiende Eeuw, (2017), 39-53.

${ }^{12}$ N. Van den Broeck, T. Lambrecht and A. Winter, 'Preindustrial welfare between regional economies and local regimes:

Rural poor relief in Flanders around 1800', Continuity and Change, in press.

${ }^{13}$ For a detailed discussion, see S. Vervust, Deconstructing the Ferraris Maps (1770-1778). A study of the map production process and its implications for geometric accuracy (Ghent University, Department of Geography, doctoral dissertation, 2016).

${ }^{14}$ A digitization (vectorization) of the Cassini map is currently carried out by the GeoHistoricalData project (https://www.geohistoricaldata.org/). See J. Perret, M. Gribaudi and M. Barthelemy, 'Roads and Cities of $18^{\text {th }}$ century France', Scientific Data, 2 (2015).

${ }^{15}$ In addition a smaller-scale $(1: 86400)$ engraved map in 21 sheets was drawn up from the Carte de Cabinet. This, less detailed, map is known as the Carte Marchande or Carte Chorographique and was intended for a larger audience.

${ }^{16}$ K. De Coene, T. Ongena, F. Stragier, S. Vervust, W. Bracke- and P. De Maeyer, 'Ferraris, the Legend', Cartographic Journal, 49 (2012), 30-42.

${ }^{17} \mathrm{~K}$. De Coene et al., 'Ferraris, the Legend', 30-42.

${ }^{18}$ K. De Coene et al., 'Ferraris, the Legend', 30-42; M. Beyaert, M. Antrop, P. De Maeyer, C. Vandermotten, C. Billen, J.M. Decroly, C. Neuray, T. Ongena, S. Queriat, I. Van Den Steen and B. Wayens, België in kaart. De evolutie van het landschap in drie eeuwen cartografie (Tielt, 2006); W. Bracke, De grote atlas van Ferraris (Tielt, 2009).

${ }^{19}$ K. De Coene et al., 'Ferraris, the Legend', 30-42.

${ }^{20}$ The LOKSTAT project (www.lokstat.ugent.be) developed at Ghent University during the past decade has systematically collected a range of quantitative data from nineteenth-century and twentieth century censuses, alongside the borders of nineteenth-century municipalities However, the LOKSTAT territorial subdivision cannot be used to organize eighteenth-century data, as parish boundaries do not necessarily correspond to municipal boundaries.

${ }^{21}$ P. De Maeyer, E. Ranson, K. Ooms, K. De Coene, B. De Wit, M. Van den Berghe, S. Vrielinck, T. Wiedemann, A. Winter, R. Kruk, I. Devos (2018), 'User-centered design of a collaborative object oriented historical GI-platform', in: The Dessimination of Cartographic Knowledge, Springer ICA series, in press.

${ }^{22}$ In some cases it would be useful to rotate as well as move the map. In the future it would therefore be practical to implement a rotation tool. 